\title{
Studies using radiolabelled aerosols in children
}

\author{
Mark L Everard
}

Although more than 20 years have passed since radioisotopes were first used to study the deposition of aerosols in the respiratory tract of children, ${ }^{1}$ such studies have only recently become relatively more common. ${ }^{2-6}$ The reason for this lies in the widespread concern regarding the use of radioisotopes for research purposes in childhood. Indeed, this concern is such that certain journals have rejected studies, not on the basis of their scientific content, but upon the editor's view that such studies are essentially unethical. However, information obtained from such studies is becoming increasingly important as the number of expensive and potent therapeutic agents being delivered by this route increases. $^{7}$

The purpose of this paper is to review radiation protection and ethical issues relating to the use of radioisotopes in research projects involving children. It then goes on to discuss technical aspects relevant to those interested in designing or interpreting radiolabelled aerosol deposition studies in children.

\section{Assessment of risks}

The International Commission on Radiological Protection (ICRP) has published guidelines for those considering exposing healthy volunteers to ionising radiation. Earlier recommendations ${ }^{8}$ were revised and updated in 1992. ${ }^{9}$ These guidelines discuss the potential harmful effects of ionising radiation, factors affecting the risk of harm, and ethical aspects of such studies.

Harmful biological effects of ionising radiation can be "deterministic" or "stochastic". ${ }^{9-11}$ Deterministic effects are those that can be attributed to direct cytotoxic effects of radiation. Below a certain threshold the possibility of causing harm will be zero. As the dose increases above this threshold value, individual cells will become damaged and die. As the dose further escalates damage will increase steeply as increasing numbers of cells within the organ are affected. The "threshold" dose varies depending upon the tissue involved, with tissues such as gonads and bone marrow being most sensitive. Providing the dose remains below the threshold dose relevant to the organ being exposed, a prediction can be made that no clinical effects will become evident. For research purposes such effects are essentially irrelevant as doses used should be below threshold values.

In contrast, there is no threshold dose for stochastic effects. These effects result from radiation-induced changes in cells which survive and remain capable of division or forming a zygote (germ cell). These effects are due to changes such as mutations, deletions and translocations in the DNA of cells and the effects may take many years to become manifest as overt malignancy or, indeed, may take one or more generations in the case of affected germ cells. There is apparently no threshold for such effects and the probability of it occurring is a function of the dose. This implies that ionising radiation at any dose is potentially harmful and may induce cancer or inherited disease at a later date. Factors influencing the magnitude of this risk depend upon factors such as the tissue irradiated, sex, age, and probably individual susceptibility. The issue of age is particularly relevant to paediatric studies.

The radiation risk to children per unit radiation dose is believed to be higher than in adults $^{12}$ since (1) children may be more sensitive to radiation (though this is now not believed to be the case with the possible exception of the juvenile thyroid); (2) the long latent period of radiation carcinogenesis (typically about 25 years) means that children are more likely to express any increased risk of carcinogenesis; and (3) children have a greater potential for passing on deleterious mutations as they may potentially have more children following exposure than adults (although genetic effects in man have not been observed).

\section{EFFECTIVE DOSE AND EFFECTIVE DOSE} EQUIVALENT

The absorbed dose for a tissue (DTR) exposed to ionising radiation is the energy absorbed per unit mass [Gray (gy) = joules absorbed per kilogram] and for a given tissue or an organ the dose is generally assumed to be absorbed uniformly. Since different ionising radiations have varying abilities to cause harm, a radiation weighting factor (WR) is used to allow for the relative biological effect of the particular radiation used. The $W_{R}$ for gamma radiation is 1 , while alpha particles have a $W_{R}$ of 20 , reflecting their substantially greater potential for causing biological effect. Thus, the equivalent dose to a tissue (HT) is given by DTR $\times W_{R}$ and is expressed as sieverts (Sv). If more than one form of radiation is involved, $\mathrm{HT}$ is the sum of the separate equivalent doses.

Since different organs vary in their tolerances 
to radiation a tissue weighting factor (WT) is used. These are 0.01 (skin), 0.05 (bladder, breast, liver, thyroid, and all other tissues), $0 \cdot 12$ (lung, red bone marrow, stomach, and colon), and $0 \cdot 2$ (gonads). The effective dose is obtained by multiplying the tissue weighting factor by the equivalent dose. For example if the lung alone received $5 \mu \mathrm{Sv}$ of radiation the effective dose would be $5 \times 0.12=0.6 \mu \mathrm{Sv}$, and this would be equivalent in terms of potential harm to uniformly irradiating the whole body with $0.6 \mu \mathrm{Sv}$. Where several organs are exposed to a source, the effective dose is the sum of the weighted equivalent doses for the particular tissues or organs receiving a dose.

Thus, the effective dose

$(\mathrm{E})=\Sigma \mathrm{W} T \times \mathrm{HT}$ (in Sv)

applies to the whole body and permits expression of the relative risk of stochastic effect occurring to be expressed whether exposure is uniform or non-uniform.

The use of this unified scale of effective dose permits intercomparison of the probable risk posed by any procedure involving ionising radiation and permits a direct comparison with the dose received by individuals from natural background sources.

\section{FACTORS AFFECTING EFFECTIVE DOSE IN} AEROSOL STUDIES

For radionuclides delivered as an aerosol, the effective dose will be influenced by a number of factors such as its residence time in the lungs and body. For example, technetium $99 \mathrm{~m}$ $\left({ }^{99 \mathrm{~m}} \mathrm{Tc}\right)$ which is the standard radioisotope used in aerosol deposition studies has a radiation half life of 6.04 hours. ${ }^{13}$ If administered as ${ }^{99 \mathrm{~m}} \mathrm{Tc}$ sodium pertechnetate it is rapidly cleared from the lungs with a half life within the lungs of 10-15 minutes. ${ }^{14}$ When administered as ${ }^{99 \mathrm{~m}} \mathrm{Tc}$ DTPA (diethylenetriaminepentaacetic acid) the half life for remaining within the lungs may be as long as 150 minutes. ${ }^{13}$ Absorption from the lungs can be enhanced by alteration in posture, disease states, exercise, and in smokers. ${ }^{1315}$ In these forms the dose absorbed by the body and individual organs can also be influenced by the frequency of micturition since they are water soluble and excreted in urine. When administered in a non-absorbable form such as ${ }^{99 \mathrm{~m}} \mathrm{Tc}$-colloidal human serum albumin (HSA), activity deposited in alveolar and nonciliated areas remains for a period well in excess of 24 hours. ${ }^{1617}$

For many aerosols as much as $80 \%$ of the dose is deposited in the upper airway and is swallowed. This fraction has a large influence on the effective dose due to exposure of the cells within the gastrointestinal tract and surrounding organs and to the slow clearance from this organ. Hence, measures to reduce the swallowed dose such as gargling and mouth washes are desirable.

Deposition of aerosol within the airways, even in peripheral regions of healthy lungs, is non-uniform ${ }^{18}$ with most occurring at sites such as bifurcations and other changes in configuration of the airways. Such uneven distribution is increased in the presence of airways disease with "hot spots" occurring in more central regions of the lungs. The impact of uneven deposition and hot spots on the calculated risk has not been extensively studied and further work is required. The absorbed dose within an organ exposed to radiation is assumed to be uniform and it is assumed that individual cells within an organ all receive an equal proportion of the dose. ${ }^{19}$ This assumption is based upon the fact that most forms of ionising radiation such as gamma rays have ranges much greater than the average cell diameter. However, most radionuclides also emit low energy Auger electrons with subcellular ranges and this may result in non-uniform exposure of cells. ${ }^{19}$ The practical significance of this is not clear, but it is likely to be small compared with other factors such as the contribution to the overall risk of the activity that is swallowed. Furthermore, as mentioned above, clearance of many radionuclides via the pulmonary circulation is rapid while mucociliary clearance also ensures that particles do not remain static within the conducting airways. Risk of possible stochastic effects for any given effective equivalent dose is based on data from a number of sources including exposure to radiation from nuclear weapons and a wide variety of medical sources over the past 80 years. Extrapolation from all these sources has potential limitations and, indeed, safe levels of annual occupational exposure have been significantly reduced recently as previous estimates of risk were shown to underestimate the risk. ${ }^{9}$ The risk of harm to an adult subject who is exposed to ionising radiation in the course of a study for research purposes has been divided into three categories by the WHO, and subsequently modified by the ICRP. ${ }^{8}$ It is expressed in terms of the effective doses involved. These categories include a corresponding category in terms of the benefit to be accrued as a result of the study. The highest risk category is for effective dose equivalents of $>10 \mathrm{mSv}$ which carry a risk of one in $10^{3}$ or more. To justify such a risk the benefits derived from the study must be "substantial and usually directly related to the saving of life or the mitigation or prevention of serious disease".

At the other end of the spectrum the risk is defined as "trivial" with a risk of one in $10^{6}$ or less. The effective dose for an adult to fall within this category is $<0.1 \mathrm{mSv}$. For children the dose is probably between a third and a half of this figure. ${ }^{8}$ Doses in that range represent that received by individuals during a few weeks from natural background sources (average annual exposure from natural source in North America is $2 \mathrm{mSv}$ ), and these doses are considerably less than variations in annual doses from natural background received by persons living in different locations. With a risk believed to be in the order of one in a million and hence generally regarded as trivial, the benefit accrued by society as a result of exposing subjects to this risk need only be "mino'r". 8

Estimation of the effective dose delivered to a patient is complex and needs to be assessed by qualified medical physicians who are capable of making the necessary dosimetric calculations 
and measurements. The use of effective dose rather than simply expressing the initial activity to be administered in $\mathrm{MBq}$ will allow ethical committees to assess the risks of particular studies in terms that are readily comprehensible, particularly as it allows the risk to be expressed in relation to the natural background or other understandable parameters such as the probability of being killed in a motor vehicle accident.

\section{Principles of research design}

The principles underlying research design when using ionising radiation can be summarised under three headings ${ }^{11}:$ (1) the potential benefits should be justified; (2) all exposures should be kept as low as reasonably achievable; and (3) dose limits specified by the ICRP should not be exceeded.

\section{JUSTIFICATION OF STUDIES}

In order to justify a study one needs not only to argue that the information obtained is important and of benefit to society, if not directly to the individual exposed, but that the information cannot be obtained in other ways. The study of aerosol delivery in childhood has only recently received attention. Various approaches have been used. Clinical studies have been performed comparing the clinical effect when utilising different methods of delivery, but these studies shed little light on deposition since they generally use $\beta_{2}$ agonists in supramaximal doses. For example, studies have shown no difference in clinical effect when $\beta_{2}$ agonists are inhaled via the nose or a mouthpiece, ${ }^{20}$ but deposition studies have shown significant differences in the dose delivered to the lungs. ${ }^{21} \mathrm{~A}$ more recent approach has been to collect drug on filters to determine the inhaled dose under different conditions using pumps to simulate the patients' respiratory patterns, ${ }^{22-24}$ or using patients themselves inhaling from different devices. ${ }^{2526}$ The pump models in particular have clarified many aspects that influence the dose delivered to a patient and have provided basic knowledge essential to designing appropriate isotope studies. However, this approach gives no information relating to where in the body the dose is deposited or the proportion of the inhaled dose that would be exhaled. For dry powder inhalers ${ }^{1427}$ and metered dose inhalers ${ }^{148}$ the exhaled dose is likely to be very low, largely due to the pattern of the inspiratory manoeuvre, but for nebulisers the exhaled fraction may be significant. ${ }^{29} 30$

It is theoretically possible to predict the pattern of deposition by combining data related to the dose inhaled with data describing the particle size distribution of an aerosol, together with a description of the inspiratory pattern, by using mathematical models developed largely by those in the field of industrial hygiene and radiation protection. ${ }^{31-33}$ Such mathematical models have been devised for adults and subsequently modified in the light of experimental data. However, there are presently no experimental data to validate or modify the models of deposition in infants and children.
Furthermore, these models assume non-diseased airways and hence are only applicable to healthy individuals. Other problems with this approach are that, in most instances, mathematical models and the experimental work against which they are judged have used monodispersed aerosols. Most therapeutic aerosols are polydispersed and as such have deposition patterns significantly different from that of a monodispersed aerosol with the same aerosol mass median diameter (AMMD). ${ }^{34}$ It is not surprising, therefore, that predicting patterns of deposition with these models is inaccurate when applied to therapeutic aerosols. Furthermore, they assume tidal breathing and further modifications are required with other delivery systems such as dry powder inhalers ${ }^{35}$ when other inspiratory manoeuvres are used.

Another potential problem with the use of filters is that the filters themselves, or associated equipment such as one-way valves, may introduce unforeseen artifacts. For instance, we have observed in one study that the increase in resistance resulting from the use of a oneway valve caused children to breath around a mouthpiece, resulting in falsely low drug delivery to the filter.

Another non-isotope method that can give slightly more direct information to the dose delivered is to use drugs that are essentially not absorbed from the gastrointestinal tract ${ }^{36}$ or to block gastrointestinal absorption by ingesting charcoal. ${ }^{3738}$ These methods would need to be validated for use in children and infants and, again, they do not provide information relating to the pattern of deposition within the airways.

Basic information related to deposition of aerosols in health and disease can be provided by an aerosol bolus dispersion method based upon photometric measuring of the number of particles inhaled and exhaled. ${ }^{173940}$ This has been extensively used by some investigators and its use is now being extended into the paediatric age group. ${ }^{41}$ This method does use monodispersed aerosols which are very different from the polydispersed aerosols used in clinical practice, and hence results produced by this method are not directly relevant to the assessment of therapeutic delivery systems. Indeed, these methods generally use particle sizes with low deposition.

Non-isotopic approaches, as cited above, can provide essential information that clarifies many of the issues particularly relevant to aerosol delivery in children and adults, but there are certain types of extremely valuable information such as the pattern of deposition that cannot be obtained, and it is likely that isotope studies will be required to clarify certain fundamental questions. However, before proceeding to these studies it is essential that investigators thoroughly understand the principles underlying aerosol therapy and, in particular, the aspects specifically relevant to children and infants.

\section{MINIMISING EXPOSURE}

The second major principle is that radiation exposure should be kept to the lowest possible 
value that does not jeopardise the quality of data obtained. Using too low a dose and failing to obtain adequate data are contrary to the principles governing the risk/benefit criteria. However, even within the "trivial" risk category the dose to which children are exposed should be minimised. Strategies to achieve this include using longer acquisition times rather than higher doses, providing that the increased time does not affect the quality of the information, ${ }^{42}$ and using the lowest number of patients compatible with obtaining an unequivocal answer. ${ }^{811}$ If necessary, the study should be terminated once statistically reliable data have been obtained. Another major influence on the dose required is the use of standard planar or single photon emission computed tomography (SPECT) imaging. ${ }^{434}$ At least one study has shown that SPECT scanning, with its three dimensional resolution, gave a statistically significant improvement in resolution when assessing central and peripheral deposition. ${ }^{45}$ Other studies have not found this, although in each case there was a tendency towards improved resolution. ${ }^{4446}$ SPECT scanning currently requires higher doses and much greater imaging time, usually $15-20$ minutes, ${ }^{1543}$ compared with the 1-2 minutes required for an image with planar imaging. Even in those few units with multiheaded gamma cameras specially designed for this purpose imaging times are still in the order of 5-10 minutes. ${ }^{43}$ Good arguments are therefore required to justify this method rather than the simpler planar imaging but, as the technology improves, this form of imaging may become the method of choice.

\section{Radiolabelled aerosol studies}

In research, radiolabelled aerosols have been most widely used to study deposition of drugs within the respiratory tract. For most studies the label is only loosely associated with the drug and probably dissociates rapidly after deposition. Hence it gives no information on the subsequent fate of the drug. True direct labelling of drugs in which an isotope is incorporated into the drug molecule has been achieved $^{4748}$ and does permit studies to assess clearance of the drug as well as deposition, but such labelling is generally a complex procedure requiring a cyclotron. Radioisotope studies have also been used to study mucociliary clearance, ${ }^{16-18}$ and the effect of factors such as disease and smoking on permeability of the respiratory tract to low molecular weight compounds such as DTPA. ${ }^{161749}$ Some studies have gone further and delivered radionuclides that are rapidly absorbed, together with ones removed by mucociliary clearance, in order to study these two clearance mechanisms simultaneously or have attempted to distinguish between clearance from alveolar and bronchial surfaces. ${ }^{17}$

Imaging using positron emission tomography $(P E T)^{50}$ permits accurate three dimensional imaging, and because it is possible to directly label both drugs ${ }^{51}$ and endogenous substances, ${ }^{50}$ this form of imaging could potentially be used for investigations into a wide range of topics related to disease processes, biological function, and drug action within the respiratory tract. ${ }^{1750}$ PET might therefore prove to be the most informative mode of imaging, but its applications are limited by the very short half life of the positron emitting nuclei and the limited number of centres with access to this form of technology.

The following discussion will be related essentially to studies aimed at assessing deposition of aerosols within the respiratory tract using conventional gamma scintigraphy.

\section{PRACTICAL ASPECTS RELATED TO}

\section{RADIOLABELLED DEPOSITION STUDIES}

As stated above, it is important that studies are carefully designed in the light of knowledge currently available in order to ensure that the results obtained are of sufficient value to justify the study. The design should also ensure that the technical aspects of such studies are carefully prepared before administering radiation to subjects. Numerous studies with adult subjects have now been published, yet many fail to describe methods and validation procedures in any detail while some totally omit fundamental aspects such as the methods used to estimate the dose delivered to the lungs. It is highly desirable that, for studies involving children, techniques should be chosen with care and methods described clearly so that comparisons can be made between studies with some validity.

The following sections will discuss techniques for labelling aerosols and then go on to discuss techniques for determining where the inhaled dose has deposited. Surprisingly, this latter subject has been least well studied and validated.

\section{LABELLING OF AEROSOLS}

Nebulised solutions

The traditional method for labelling drug solutions delivered from both jet and ultrasonic nebulisers has been the so called "soap" method in which a drug solution is mixed with a radionuclide. It has been assumed, quite reasonably, that the droplets generated by the nebuliser contain drug and radiolabel in proportions determined by the solution from which they are generated. Since the particle size characteristics of the aerosol are largely determined by the design of the nebuliser and the driving gas flow used, it is also reasonable to assume that the particle size characteristics will be little altered by the addition of most radionuclides. Relatively few studies have attempted to determine whether these assumptions are valid for a particular combination of drug and radionuclide, but those that have found that the drug did follow the label ${ }^{5253}$ and the radioisotope had little effect on the particle size characteristics of the aerosol. ${ }^{5254}$ As the radiolabel travels with the drug in droplets but is not bound to the drug, information on deposition can be obtained but, since drug and label dissociate rapidly after deposition, these 
studies will not provide any information regarding clearance of the drug following deposition. It is possible to directly label some drugs such as pentamidine ${ }^{49}$ and hence the fate of the drug once inhaled can be assessed (providing the labelling involves isotope substitution), but it is doubtful if information relating to the pattern of deposition can be improved.

The "soup method" is, of course, not suitable for drug suspensions such as the steroid preparations for use with nebulisers, since the drug may not be uniformly distributed in either the suspension or the droplets generated by the nebuliser.

Studies utilising jet nebulisers should take into account the great variation in nebuliser output and particle size that can occur between nebulisers of the same make, even those from the same batch. ${ }^{5556}$ Some manufacturers have started to address this problem by using improved moulding techniques. Another potential problem, ignored in many studies, has been the use of inappropriate methods for obtaining particle size measurements. It is frequently not realised that significant drying of wet aerosols occurs when using cascade impactors, resulting in much finer droplet sizes than would be obtained with laser particle sizers ${ }^{5758}$ which can measure the particle size characteristics of the aerosol as it leaves the nebuliser. Thus, laser particle sizing is the method of choice for measuring the output from nebulisers. ${ }^{58}$ This potential for aerosols to change in size due to hygroscopic growth or drying also means that the characteristics of an aerosol can be significantly altered if a length of tubing is introduced between the nebuliser and patient. For dry powder inhalers and metered dose inhalers cascade impactors or multistage impingers are used.

It is well known that intersubject variation can be very large when studying deposition of aerosol from a nebuliser. It should be remembered that intrasubject variability is also significant when studies utilising nebulisers are repeated, and this must be taken into account when deciding upon subject numbers. ${ }^{59}$ Much of this variability probably stems from differences in inhalation patterns, ${ }^{60}$ and hence variability may be reduced to some extent by using predetermined patterns of inhalation, but this does not mimic the clinical situation.

\section{Metered dose inhalers and dry powders}

During the past five years there has been a relative explosion of deposition studies using Kohler's "direct" labelling technique ${ }^{61}$ and its subsequent modifications and improvements. Previous studies had used one of two approaches. One involved direct labelling of the ipratropium bromide molecule using ${ }^{77} \mathrm{Br}$ for the bromide moiety, ${ }^{48}$ while others have used labelled Teflon particles to replace drug particles. ${ }^{6263}$ However, the chemical and physical properties of a system that uses Teflon rather than drug is almost certainly different from one containing active drug. In 1988 Kohler et al described a method in which ${ }^{99 \mathrm{~m}} \mathrm{Tc}$ was added to a metered dose inhaler canister, together with propellants, surfactant, and drugs. ${ }^{61}$ Subsequent workers ${ }^{6465}$ have modified and improved the technique so that no alterations to the contents of the canister are required other than the addition of the radiolabel. These methods are not applicable to all metered dose inhaler products and hence careful in vitro radiation is essential before undertaking deposition studies. ${ }^{66}$ The term "direct labelling" is misleading in that the radiolabel is not part of the drug structure but is associated either with the micronised drug particles or the surfactant coating, depending upon the drug/surfactant combination used..$^{66}$ An increasing number of these studies, using various drugs, has been published over the past few years. ${ }^{1427286768}$ Similar techniques have been used for labelling powders, ${ }^{14276970}$ although for some powders particular adaptations are required. ${ }^{25}$

As noted above, essential to these techniques is in vitro verification of the accuracy of the labelling techniques and details of this have frequently been omitted in publications. Accuracy of labelling should be confirmed by means of a cascade impactor or similar particle sizing device. It should be shown that (a) the radiolabel follows the drug - that is, that they are in equal proportions on each stage - and (b) the radiolabelling procedure does not alter the dose and particle size distribution of the aerosol. Published data show that the particle size distribution may be affected to some extent by the process and that there is frequently a difference between the distribution of the radiolabel and drug. ${ }^{2768-70}$ These differences are generally small but may have some effect on the results obtained with the gamma camera.

As in the case of jet nebulisers, inhalation patterns can be prescribed or spontaneous. For example, subjects using powder inhalers may inhale at maximal inspiratory flows as advocated in the clinical setting or be taught to aim for a predetermined inspiratory flow. ${ }^{1527}$

\section{ASSESSMENT OF DEPOSITION}

In any experiment a number of parameters must be assessed. These include: (a) the dose deposited within the respiratory tract of the subject, (b) the pattern of deposition within the body, and (c) the pattern of deposition within the lungs.

A large number of methods of analysing data and presenting the results have been used in studies in adult subjects. As a result it is frequently difficult to compare the results obtained in different studies in any meaningful way. ${ }^{58}$

\section{Total delivered dose}

Total drug delivery nebulisers can be determined from the counts obtained from the apparatus before and after nebulisation once correction for background and decay are made. This assumes that all of the radiolabel not deposited within the body is retained within the apparatus, which must therefore include 
filters to trap aerosol. With tidal breathing, as when using jet nebulisers, significant quantities of the inspired dose are exhaled and these must be collected. Some investigators have tried to quantify the total dose deposited by using a controlled pattern of breathing and drug collection on filters, ${ }^{71}$ or by modifying the aerosol bolus/photometric method to quantify the dose deposited. ${ }^{72}$

For studies using dry powders and metered dose inhalers the "administered dose" of activity can be obtained by collecting a dose onto a filter or in a closed container. It must be remembered that as much as $20 \%$ of the nominal dose is retained within the actuator when using metered dose inhalers ${ }^{142865}$ and, similarly, for dry powder inhalers significant amounts of drug remain within the device. ${ }^{1427}$ The retained dose should be included in the "total dose".

Unfortunately, many studies do not give a figure for the total dose delivered but give an "intrapulmonary" dose estimated from the dose measured using a gamma camera corrected for tissue attenuation which is very dependent on the method used.

\section{Distribution of deposited drug within the body}

The measurement of the absolute quantity of radioactivity within the respiratory tract is complicated by attenuation and scatter of gamma rays within the body. In addition, for planar imaging correction must be made for the effect of distance of activity from the gamma camera as deposition occurs in three dimensions. If a simple anterior image is obtained, activity deposited posteriorly would generate fewer counts per second than an equal quantity deposited anteriorly. To correct for this, the geometric mean of counts obtained from anterior and posterior images of the chest is calculated. This measurement is largely independent of depth.

Several methods have been devised in an attempt to correct for attenuation. These include the administration of a known dose of radiation intravenously in the form of microaggregates which are assumed to be entirely trapped within the pulmonary circulation ${ }^{295973}$; the use of "phantoms" in which a radiation source is placed within a block of material designed to simulate the chest wall ${ }^{745}$; calculations based upon reference values for different chest thicknesses ${ }^{65}$; and the use of "flood sources"7677 to obtain transmission images for each subject. Attenuation of activity in the stomach and oropharynx is greater than that for the chest.

The microaggregate method is often regarded as the "gold standard" for determining attenuation within the chest but there are inevitably some differences between the distribution of injected microaggregates and radiolabelled therapeutic aerosols. ${ }^{73}$ More importantly, this method is probably unsuitable for studies involving children because of the increased radiation dose required. Little work has been done to assess the accuracy of the other methods until recently, but a recent study ${ }^{77}$ in adults showed that phantom methods significantly underestimated the dose within the lung. Perhaps more importantly, the same correction factor is used for all subjects which can introduce significant non-systematic inaccuracies. ${ }^{72}$ Calculation of an attenuation factor using a "flood source" tended to slightly overestimate the dose within the lungs but was considerably more accurate. This method involves recording an image of a source of gamma rays, usually ${ }^{99 \mathrm{~m}} \mathrm{Tc}$, using a gamma camera. The subject is then placed between the gamma camera and the flood source and the image recorded. The attenuation factor for each subject is calculated from the difference in counts ${ }^{76}$ and is specific for the individual gamma camera. Further advantages of this method are that the lung outlines can be defined and attenuated factors for both head and stomach can be calculated, though this is rarely done. The additional radiation exposure using this method is low. The study found that two "build-up factor" methods which have not been used in deposition studies were the most accurate, but these are more complicated than the geometric mean flood source method ${ }^{76}$ which was felt to be sufficiently accurate. ${ }^{77}$

Transmission scans do not provide information that would allow correction for scatter but it appears that, for isotopes such as ${ }^{99 \mathrm{~m}} \mathrm{Tc}$, ignoring the effects of scatter does not lead to excessive errors. ${ }^{42}$

Deposition within the upper airways is frequently assumed to be the difference between the calculated lung dose and the delivered dose and is rarely directly quantified.

\section{Distribution within the lungs}

For planar studies it has been conventional to divide the images into central and peripheral regions of the lung with the implication that central regions contain predominantly large airways and the peripheral regions predominantly alveoli, but because of the two dimensional nature of the image there is inevitably much overlap of conducting airways and alveoli, particularly in the central region. The "penetration index" (ratio of peripheral to central deposition) obtained from planar images is therefore probably relatively insensitive to changes in patterns of deposition. Moreover, there has been no standard method of defining central and peripheral regions and many arbitrary methods for dividing the lung into central and peripheral regions have been used. This makes it extremely difficult to compare results from different investigators. ${ }^{58}$

In an attempt to define the dose deposited in non-ciliated regions, formulations such as ${ }_{99 \mathrm{~m}}$ Tc-HSA, which are absorbed very slowly from the alveoli, have been used. Images obtained immediately after delivery are compared with those 24 hours later allowing for decay of activity. The assumption has been that residual activity lies within the alveoli, the activity within the conducting airways having been removed by mucociliary clearance. ${ }^{1618}$ This assumption has recently been shown to be an oversimplification ${ }^{18}$ and clearance of such products is probably more complex than was previously 
assumed. ${ }^{1873}$ This technique also greatly increases the residence time of the radionuclide within the lung.

Perhaps of more importance is the finding that it is frequently unclear what the significance of a "good" penetration index is. For a drug such as pentamidine good peripheral deposition is obviously desirable as its site of action is the alveoli. For drugs such as steroids and antibiotics in cystic fibrosis, their site of action is likely to be the conducting airways and hence alveolar deposition is probably undesirable. However, the surface area of distal airways is much greater than that of earlier generations and in order to deliver adequate doses to smaller conducting airways, significant alveolar deposition is likely since current devices, which produce polydisperse aerosols, cannot accurately target specific regions. For highly soluble drugs such as bronchodilators, redistribution of drug from central to more peripheral regions through the bronchial circulation may obviate the need for good peripheral deposition. ${ }^{78}$

As mentioned previously, the use of SPECT scanning has, in some studies, improved resolution when compared with conventional planar scanning, but the increased dose and complexity involved makes it debatable whether its use can be justified routinely in children; however, this may change with improved equipment. A further technical problem with SPECT is that the relatively long acquisition time causes problems with radionuclides such as ${ }^{99 \mathrm{~m}} \mathrm{Tc}$-labelled sodium pertechnetate that are rapidly cleared from the lungs and subsequently appear in the pulmonary circulation.

In summary, radiolabelled deposition studies can be performed in children using a level of radiation exposure equivalent to just a few weeks of radiation from natural sources. ${ }^{7}$ The risk from such exposure is very low but, in order to justify even this small risk, studies must be carefully designed to ensure that unnecessary investigations are avoided and that useful data are provided that cannot be obtained in other ways (table). This requires a thorough understanding of the use of aerosols in childhood, the technical limitations of devices, and the provision of the expert technical assistance provided by medical physicists and technologists.

The author acknowledges Dr I Gonda for his helpful comments.

Aspects of study design to be considered before commencing studies on deposition of radiolabelled drugs

(1) Factors affecting delivery from the type of device to be studied should be thoroughly understood

(2) Patient and delivery system factors known to be relevant to children should be considered

(3) Radiolabelled aerosols should only be used to answer important questions that cannot be answered in an alternative way

(4) The minimum dose compatible with good quality should be used

(5) The minimum number of subjects consistent with statistically reliable data should be used

6) The radiolabel must follow the drug (at least before deposition) and must not alter the characteristics of the aerosol

(7) A method for correcting for attenuation should be used that allows correction factors to be calculated for each patient and which has been shown to produce accurate results

(8) Internal checks should be employed such as calculating lung dose (a) directly from gamma camera images and (b) as percentage of dose "deposited" obtained from pre and post images of device and filters

(9) Accurate advice must be obtained from medical physicists and from individuals with previous experience in the field
1 Alderton PO, Secker-Walker RH, Strominger DB, Markham J, Hill RL. Pulmonary deposition of aerosols in children with cystic fibrosis. $\mathcal{F}$ Pediatr $1974 ; 84: 479-84$.

2 Murakami G, Igarashi T, Adachi Y, Matsuno M, Adachi Y, Sawai $M$, et al. Measurement of bronchial hyperreactivity in infants and preschool children using a new method. Ann Allergy 1990;64:383-7.

3 O'Doherty MJ, Thomas SHL, Gibb D, Page CJ, Harrington $\mathrm{C}$, et al. Lung deposition of aerosol nebulised pentamidine in children. Thorax 1993;48:220-6.

4 Chua HL, Collis GG, Maxwell L, Chan K, Langford JH, Newbury AM, et al. The effect of age and method of delivery on aerosol deposition in children (abstract). Am Rev Respir Dis 1991;143:A706.

5 Marshall LM, Francis PW, Khafagi FA. Aerosol deposition in cystic fibrosis using an aerosol conservation device and a conventional jet nebulizer. $\mathcal{f}$ Paediatr Child Health 1994; 30:65-7.

6 Mukhopadhay S, Staddon GE, Eastman C, Palmer M, Rhys Davies E, Carswell F. The quantitative distribution of nebulized antibiotic in the lung in cystic fibrosis. Respir Med 1994;88:203-11.

7 Thomas SHL, Batchelor S, O'Doherty MJO. Therapeutic aerosols in children. BMF 1993;307:245-7.

8 International Commission on Radiological Protection (ICRP). Recommendations of the ICRP. ICRP Publication 26. Annals of the ICRP. Vol 1:3. Oxford: Pergamon Press, 1977

9 International Commission on Radiological Protection (ICRP). Radiological protection in biomedical research. ICRP Publication 62. Annals of the ICRP. Oxford: Pergamon Press, 1992.

10 International Commission on Radiological Protection (ICRP). Recommendations of the ICRP. ICRP Publication 60. Annals of the ICRP. Vol 21: 1-3. Oxford: Pergamon Press, 1991

11 Poston JW. Application of the effective dose equivalent to nuclear medicine patients. $f$ Nucl Med 1993;34:714-6.

12 Huda W, Scrimger JW. Irradiation of volunteers in nuclear medicine. f Nucl Med 1989;30:260-4.

13 Atkins HL, Weber DA, Susskind H, Thomas SR. MIRD dose estimate report No. 16: Radiation absorbed dose from technetium-99m-diethylenetriaminepentaacetic acid aerosol. ₹ Nucl Med 1992;33:1717-9.

14 Melchor R, Biddiscombe MF, Mak VHM, Short MD Spiro SG. Lung deposition patterns of directly labelled salbutamol in normal subjects and in patients with reversible airflow obstruction. Thorax 1993;48:506-11.

15 Summers QA. Inhaled drugs and the lung. Clin Exp Allergy 1991;21:259-68.

16 Gonda I. Diagnostic aerosols: current status and future prospects. Aerosol Sci Technol 1993;18:250-6.

17 Bennett WD, Ilowite JS. Dual pathway clearance of $99 \mathrm{~m}$ Tc-DTPA from the bronchial mucosa. Am Rev Respir Dis 1989;139:1132-8.

18 Gonda I. Targeting by deposition. In: Hickey AJ, ed. Pharmaceutical inhalation aerosol technology. New York: Marcel Dekker, 1992:61-82.

19 Makrigiorgos GM, Adelstein SJ, Kassis AI. Limitations of conventional internal dosimetry at the cellular level. $\mathcal{f}$ Nucl Med 1989;30:1856-64.

20 Stevenson RD, Wilson RSE. Facemask or mouthpiece for delivery of nebulized bronchodilator aerosols? $\mathrm{Br} \mathcal{F}$ Dis Chest 1981;75:88-90.

21 Everard ML, Hardy JG, Milner AD. Comparison of nebulised aerosol deposition in the lungs of healthy adults following oral and nasal inhalation. Thorax 1993;48: 1045-6.

22 Everard ML, Clark AR, Milner AD. Drug delivery from jet nebulisers. Arch Dis Child 1992;67:586-91.

23 Everard ML, Clark AR, Milner AD. Drug delivery from holding chambers with attached facemask. Arch Dis Child 1992;67:580-5.

24 Everard ML, Stammers J, Hardy JG, Milner AD. New aerosol delivery system for neonatal ventilator circuits. Arch Dis Child 1992;67:826-30.

25 Collis GG, Cole CH, Le Souef PN. Dilution of nebulised aerosols by air entrainment in children. Lancet 1990;336: 341-3.

26 Lodrup KC, Nikander K, K-H Carlsen. How much nebulised budesonide reaches infants and toddlers? Arch Dis Child 1992;67:1077-9.

27 Borgstrom L, Bondesson E, Moren F, Newman SP. Lung deposition of budesonide inhaled via Turbuhaler. A comparison with terbutaline sulphate. Eur Respir $\mathcal{f} 1994 ; 7$ 69-73.

28 Hardy JG, Everard ML, Coffiner M, Fossion J. Lung deposition of a nacystelyn metered dose inhaler formulation. f Aerosol Med 1993;6:37-44.

29 Smaldone GC, Fuhrer J, Steigbigel RT, McPeck M. Factors determining pulmonary deposition of aerosolized pentamidine in patients with human immunodeficiency virus tamidine in patients with human immunodeficienc
infection. Am Rev Respir Dis 1991;143:727-37.

30 Clay MM, Clarke SW. Effect of nebulized aerosol size on lung deposition in patients with mild asthma. Thorax 1987 42:190-4.

$31 \mathrm{Xu}$ GB, Yu CP. Effects of age on deposition of inhaled aerosols in human lung. Aerosol Sci Technol 1986;5:349-57.

32 Thomas RG. Regional human lung dose following inhalation of radioactive particles at ages one month to adulthood. Ann Occup Hyg 1988;32(Suppl 1):1025-33.

33 Swift DL. Age-related scaling for aerosol and vapour deposition in the upper airways of humans. Health Phys 1989;57(Suppl 1):293-7. 
34 Gonda I. Study on the effects of polydispersity of aerosols on regional deposition in the respiratory tract. $\mathcal{f}$ Pharm Pharmacol 1981:33:52P.

35 Egan M, Clark AR. Modelling the deposition of inhaled powdered drug aerosols. F Aerosol Sci 1994;25:175-86.

36 Salmon B, Wilson NM, Silverman $M$. How much aerosol reaches the lungs of wheezy infants and toddlers? Arch Dis Child 1990;65:401-3.

37 Borgstrom L, Newman SP, Weisz A, Moren F. Pulmonary deposition of inhaled terbutaline: comparison of scanning gamma camera and urinary excretion methods. 7 Pharm Sci 1992;81:753-5.

38 Hindle $M$, Newton DAG, Chrystyn $H$. Investigations of an optimal inhaler technique with the use of urinary an optimal inhaler technique with the use of urinary salbutamol excretion as a measure of relative

39 Stahlhofen W, Gebhart J, Heyder J. Experimental determination of regional deposition of aerosol particles in the human respiratory tract. Am Ind Hyg Assoc $\mathcal{F} 1980$; 41:385-98.

40 Anderson PJ, Blanchard JD, Brain JD, Feldman HA, McNamara JJ, Heyder J. Effect of cystic fibrosis on inhaled aerosol boluses. Am Rev Respir Dis 1989;140:1317-24.

41 Schulz A, Tuch T, Brand P, Schulz H, Mutius E, Erdl R, et al. Aerosol bolus dispersion during breathing in healthy children. $₹$ Aerosol Med 1993;6(Suppl):65.

42 Gonda I. Absolute and relative quantification of deposition by scintigraphy. $\mathcal{F}$ Biocharm Sci 191-7.

43 Chan HK. Use of single photon emission computed tomography in aerosol studies. $\mathcal{F}$ Aerosol Med 1993;6:23-32.

44 Perring S, Summers QA, Fleming JS, Nassim MA, Holgate ST. A new method of quantification of the pulmonary regional distribution of aerosols using combined CT and SPECT and its application to nedocromil sodium administered by metered dose inhaler. Br 7 Radiol 1994;67: 46-53.

45 Phipp P, Gonda I, Bailey D, Borham P, Bautovich G, Anderson S. Comparison of planar and tomographic gamma scintigraphy to measure the penetration index of inhalation aerosols. Am Rev Respir Dis 1989;139:1516-23.

46 Logus JW, Trajan M, Hooper HR, Lentle BC, Mann SFP. Single photon emission tomography of lungs imaged with Tc-labelled aerosol. $¥$ Can Assoc Radiol 1984;35:133-8.

47 O'Doherty MJ, Thomas SHL, Page CJ, Blower PJ, Bateman NT, Nunan TO. Disposition of nebulized pentamidine measured using direct radiolabel ${ }^{123}$ I-iodopentamidine. measured using direct radiolabe

48 Spiro SG, Singh CA, Tolfree SEJ, Partridge MR, Short MD. Direct labelling of ipratropium bromide aerosol and its deposition pattern in normal subjects and patients with chronic bronchitis. Thorax 1984;39:432-5.

49 Huchon GJ, Montgomery AB, Lipavsky A, Hoeffel JM, Murry JF. Respiratory clearance of aerosolized radioactive solutes of varying molecular weight. $\mathcal{F}$ Nucl Med 1987;28: 894-902.

50 Wollmer P, Pride NB, Rhodes CG, Sanders A, Pike VW, Palmer AJ, et al. Measurement of pulmonary erythromycin concentration in patients with lobar pneumonia by means of positron tomography. Lancet 1982;ii:1361-4.

51 Schuster DP. Positron emission tomography: theory and its application to the study of lung disease. Am Rev Respir Med 1989;139:818-40.

52 Thomas SHL, O'Doherty MJ, Graham A, Blower PJ, Geddes DM, Nunan TO. Pulmonary deposition of nebulised amiloride in cystic fibrosis: comparison of two nebulisers. Thorax 1991;46:717-21.

53 Witten ML, Bowers MC, Hall JN, Quan SF, Shen $Q$ Lemen RJ. A rapid analytical method for measuring drug

54 O'Doherty MJ, Thomas S, Page C, Clark AR, Mitchell D, Heduan $\mathrm{E}$, et al. Does ${ }^{99} \mathrm{Tc}^{\mathrm{m}}$ human serum albumin alter the characteristics of nebulised pentamidine isethionate? Nucl Med Commun 1989;10:523-9.

55 Newman SP, Pellow PGD, Clarke SW. Droplet size distributions of nebulised aerosols for inhalation therapy. Phys Physiol Meas 1986;7:139-46.
56 Alvine GF, Rogers P, Fitzsimmons KM, Ahrens RC. Disposable nebulizers. How reliable are they? Chest 1992: 101:316-9.

57 Ho KKL, Kellaway IW, Tredree RL. Particle size analysis of nebulised aerosols using Fraunhoffer laser diffraction and inertial impaction methods. F Pharm Pharmacol 1986; (Suppl):26P.

58 Clark AR. The use of laser diffraction for evaluation of the aerosol clouds generated by medical nebulizers. Int $\mathcal{f}$ Pharm 1994 (in press).

59 Thomas SHL, O'Doherty MJ, Page CJ, Numan TO. Variability in the measurement of nebulized aerosol deposition in man. Clin Sci 1991;81:767-75.

60 Bennett WD. Aerosolized drug delivery: fractional deposition of inhaled particles. F Aerosol Med 1991;4:223-7.

61 Kohler D, Fleischer W, Matthys H. New method for easy labelling of $\beta_{2}$-agonists in metered dose inhalers with technetium $99 \mathrm{~m}$. Respiration 1988;53:65-73.

62 Newman SP, Millar AB, Lennard-Jones TR, Moren F, Clarke SW. Improvement of pressurised aerosol deposition with Nebuhaler spacer device. Thorax 1984;39:935-41.

63 Zainudin BMZ, Biddiscombe M, Tolfree SEJ, Short M Spiro SG. Comparison of bronchodilator responses and deposition patterns of salbutamol inhaled from a presdeposition patterns of salbutamol inhaled from a pressurised metered dose inhaler, as a dry powder

64 Summers QA, Clark AR, Hollingworth A, Fleming J, Holgate ST. The preparation of a radiolabelled aerosol of nedocromil sodium for administration by metered dose inhaler that accurately preserves particle size distribution of the drug. Drug Invest 1990;2:90-8.

65 Newman SP, Clark AR, Talee N, Clarke SW. Pressurised aerosol deposition in the human lung and without an "open" spacer. Thorax 1989;44:706-10.

66 Clarke JG, Farr SJ, Wicks SR. Technetium-99m labelling of suspension type pressurised metered dose inhalers comof suspension type pressurised metered dose inhalers comprising various

67 Vidgren M, Paronen P, Vidgren P, Nuutinen J, Vainio P. Effect of the new spacer-device on the deposition of the inhaled metered dose aerosol. Pharmazie 1990;45:922-4.

68 Newman SP, Clarke SW. Bronchodilator delivery from Gentlehaler, a new low velocity pressurized aerosol inhaler. Chest 1993;103:1442-6.

69 Newman SP, Moren F, Trofast E, Talee N, Clarke SW. Deposition and clinical efficacy of terbutaline sulphate
from Turbuhaler, a new multi-dose powder inhaler. Eur from Turbuhaler, a new

70 Thorsson, Newman SP, Weisz A, Trofast E, Moren F. Nasal distribution of budesonide inhaled via a powder inhaler. Rhinology 1993;31:7-10.

71 Smaldone GC, Fuhrer J, Steigbigel RT, McPeck M. Factors determining pulmonary deposition of aerosolized pentamidine in patients with human immunodeficiency virus infection. Am Rev Respir Dis 1991;143:727-37.

72 Messina MS, Smaldone GC. Evaluation of quantitative aerosol techniques for use in bronchoprovication studies. aerosol techniques for use in bronchop

73 Cross CE, Hornof WJ, Koblik PD, Fisher PE. Aerosol deposition: practical considerations of methodology for direct measurement of aerosol delivery to the lung bronchiolar-alveolar surfaces. F Aerosol Med 1992;5:39-45.

74 Asmundsson T, Johnson RF, Kilburn KH, Goodrich JK. Efficiency of nebulizers for depositing saline in human lung. Am Rev Respir Dis 1973;108:506-12.

75 Ruffin RE, Dolovich MB, Wolff RK, Newhouse MT. The effects of preferential deposition of histamine in the human airway. Am Rev Respir Dis 1978;117:485-92.

76 Macey DJ, Marshall R. Absolute quantitation of radiotracer uptake in the lungs using a gamma camera. $₹ \mathrm{Nucl} \mathrm{Med}$ 1982;23:731-5

77 Forge NI, Mountford PJ, O'Doherty MJ. Quantification of technetium-99m lung radioactivity from planar images. Eur F Nucl Med 1993;20:10-15.

78 Matthys H. Nebulizer possibilities and limitations. $\mathcal{f}$ Aerosol Med 1991;4:157-62. 